\title{
Assessing Anthracene and Arsenic Contamination within Buffalo River Sediments
}

\author{
Adrian Gawedzki and K. Wayne Forsythe \\ Department of Geography, Ryerson University, Toronto, ON, Canada M5B 2K3 \\ Correspondence should be addressed to K. Wayne Forsythe, forsythe@geography.ryerson.ca
}

Received 30 August 2011; Accepted 5 December 2011

Academic Editor: L. M. Chu

Copyright () 2012 A. Gawedzki and K. W. Forsythe. This is an open access article distributed under the Creative Commons Attribution License, which permits unrestricted use, distribution, and reproduction in any medium, provided the original work is properly cited.

\begin{abstract}
Anthracene and arsenic contamination concentrations at various depths in the Buffalo River were analyzed in this study. Anthracene is known to cause damage to human skin and arsenic has been linked to lung and liver cancer. The Buffalo River is labelled as an Area of Concern defined by the Great Lakes Water Quality Agreement between Canada and the United States. It has a long history of industrial activity located in its near vicinity that has contributed to its pollution. An ordinary kriging spatial interpolation technique was used to calculate estimates between sample locations for anthracene and arsenic at various depths. The results show that both anthracene and arsenic surface sediment $(0-30 \mathrm{~cm})$ is less contaminated than all subsurface depths. There is variability of pollution within the different subsurface levels $(30-60 \mathrm{~cm}, 60-90 \mathrm{~cm}, 90-120 \mathrm{~cm}, 120-150 \mathrm{~cm})$ and along the river course, but major clusters are identified throughout all depths for both anthracene and arsenic.
\end{abstract}

\section{Introduction}

The Buffalo River is labelled as an Area of Concern (AOC) defined by the Great Lakes Water Quality Agreement between Canada and the United States and will experience a proposed $\$ 39$ million cleanup [1]. Both private and public investors are part of this major cleanup effort that is set to begin in the spring of 2011. The major contributors to the cleanup effort include the United States Environmental Protection Agency (USEPA), the New York State Department of Environmental Conservation (NYSDEC), the United States Army Corps of Engineers (USACE), and the Buffalo Niagara Riverkeeper (BNRK). The plan outlines the removal of almost a million cubic yards of contaminated sediment through a dredging process [1].

Both anthracene and arsenic have health concerns associated with them so it is not ideal to have large clusters of contamination within the rivers sediment. Anthracene is a polycyclic aromatic hydrocarbon (PAH) and arsenic is a metalloid. Both contaminants were analyzed to better depict the true contamination within Buffalo River sediments.

Anthracene generally enters a person's body through breathing contaminated air; however, one can be exposed to it by eating or drinking food and water that is contaminated. Degradation of benthos, loss of fish and wildlife habitat, and health concerns related to consumption of the river's carp are some of the concerns related to the contamination of the Buffalo River [2]. Once in your body, anthracene can target fat tissues or organs including the kidneys and liver [3].

Djomo et al. [4] conducted a controlled experiment with Zebrafish to analyze their uptake and depuration of PAHs including anthracene. Two control tanks were used, one with clean water, the other with contaminated water. The results indicated that a rapid uptake of contamination is noticed within zebrafish when exposed to the contaminated tank. Anthracene had the highest uptake rate in zebrafish within the first 24 hours when compared to the other PAHs studied.

Baumard et al. [5] conducted research on PAHs in sediments and mussels in the western Mediterranean Sea. Twenty-three sample locations were used in the study to report on 26 PAHs. The authors found that PAHs with low molecular weight, such as anthracene, were mainly absorbed as dissolved compounds rather than absorbed by particulate matter through the digestive route [5].

Arsenic is tasteless and odourless in drinking water, making it difficult to detect by a consumer. Health Canada 
and the International Agency for Research on Cancer consider arsenic a human cancer-causing agent. With long-term exposure to arsenic, some effects include thickening and discoloration of the skin, nausea and diarrhea, decreased production of blood cells, abnormal heart rhythm and blood vessel damage, or numbness in the hands and feet [6]. Concentrations of arsenic in the Buffalo River surface sediment are mostly between the TEL and PEL levels [7].

Berg et al. [8] conducted a study that analyzed the human health threat of arsenic contamination in groundwater and drinking water in Vietnam. The study area of Hanoi consisted of sixty-eight sample locations from private tubewells and 8 sample locations from the major drinking water plants. The average arsenic concentration was $159 \mu \mathrm{g} / \mathrm{L}$ in rural groundwater samples from private small scale tubewells, while the groundwater that was used directly as drinking water in a highly affected rural area had average arsenic concentration levels of $430 \mu \mathrm{g} / \mathrm{L}$ [8]. The results indicate that chronic arsenic poisoning is a significant risk to millions of people who are consuming untreated groundwater.

Mazumder et al. [9] analyzed arsenic levels in drinking water and the prevalence of skin lesions in West Bengal, India. The arsenic level in 7683 participant's drinking water was measured in addition to their keratosis and hyperpigmentation levels. The results indicated that there is a relationship between arsenic levels in water and skin lesions, specifically, "high amounts of arsenic in the tubewell water were associated with keratosis and hyperpigmentation" [9]. The mean arsenic concentration was $210 \mu \mathrm{g} / \mathrm{L}$ for individuals that did not have any skin lesions. Also, there were cases where participants had skin lesions and low levels of arsenic in their drinking water. The authors suggest that the reasoning may be related to the source of water; therefore, these individuals were likely to be exposed to arsenic in their drinking water from places outside the sample locations such as their workplace [9].

The Canadian Council of Ministers of the Environment (CCME) has identified two measures, the Threshold Effect Level (TEL) and the Probable Effect Level (PEL) that are effective in assessing sediment contamination. Contamination concentrations below the TEL are where adverse biological effects are expected to occur rarely, while concentrations above the PEL are where adverse biological effects are expected to occur frequently. Forsythe et al. [7], Forsythe and Marvin [10], and Rodriguez [11] all used PEL and TEL values in their research. Kriged results were categorized into three separate groups: below TEL, TEL to PEL, and above PEL, with three class ranges in each group. This gives meaning to the results as they can be compared to the guidelines set by the CCME [10, 11]. The TEL is $46.9 \mathrm{ng} / \mathrm{g}$, and the PEL is $245 \mathrm{ng} / \mathrm{g}$ for anthracene, while the TEL is $5.9 \mu \mathrm{g} / \mathrm{g}$ and the PEL is $17 \mu \mathrm{g} / \mathrm{g}$ for arsenic.

\section{Study Area}

The Buffalo River (Figure 1) flows into Lake Erie in the City of Buffalo, New York. Lake Erie is one of the five Laurentian Great Lakes which contain one-fifth of the world's fresh

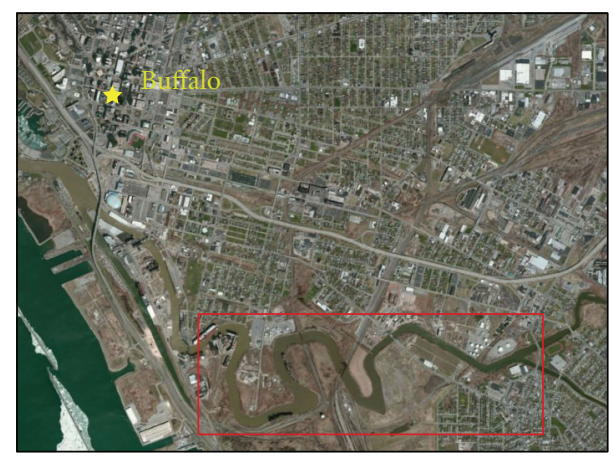

FIgURE 1: Area of concern. The section of the Buffalo River that is located within the highlighted rectangular box serves as the study area for this project. Data source: Google Maps (2009).

surface water with only the polar ice caps and Lake Baikal in Siberia containing more [12]. The Buffalo River is better known as being part of Buffalo Creek in the western New York area; however, within the vicinity of the City of Buffalo, it is known as the Buffalo River. This watershed has two main tributaries: Cazenovia Creek and Cayuga Creek.

The Buffalo River has a long history of heavy industrial activity that spans decades and has raised concerns about the river's contamination. Forsythe et al. [7], Irvine and Pettibone [13], and Canfield et al. [14] suggest the Buffalo River AOC has been negatively affected by industrial activity, leading to the contamination of its sediments. The river was used as a dumping ground for all types of waste with discharges connected directly to the river. ExxonMobil Corporation, Honeywell Corporation, and PVS Chemicals are major contributors to the Buffalo River's environmental damage and are being pursued for these damages [1]. Contamination within Buffalo River sediment is not uniform. There are sections of the Buffalo River that have high pollution levels, above the TEL and PEL for multiple contaminants including lead, nickel, and mercury [7].

\section{Data Collection}

The data for this study were collected in 2005 by the New York State Department of Environmental Conservation with assistance from the United States Army Corp of Engineers, the Buffalo Niagara Riverkeeper, and the United States Environmental Protection Agency [15]. Sediment core samples were collected to assess the impairment of habitat due to chemical contamination of shallow sediments, chemical contamination in recently deposited sediments, and historical chemical contamination in undisturbed sediment [15]. No data were collected on contamination levels in the river water.

Both surface (core samples up to $30 \mathrm{~cm}$ in depth) and subsurface sediments (core samples below a depth of $30 \mathrm{~cm}$ ) were analyzed. During collection, a sampling bias was exercised towards areas known to be affected by tributaries, outfalls, and other industrial sources or historical spills [15]. Previously sampled areas were also considered for comparison purposes. A total of 182 sample cores were extracted 
TABLE 1: Anthracene sediment sampling location statistics for the Buffalo River (ng/g).

\begin{tabular}{lccccc}
\hline Depth $(\mathrm{cm})$ & No. of sites & Min* & Max & Average & SD \\
\hline $0-30$ & 111 & 19 & 12000 & 422.38 & 1763.79 \\
$30-60$ & 34 & 57 & 10000 & 2251.88 & 2773.84 \\
$60-90$ & 33 & 64 & 10000 & 4323.16 & 3162.62 \\
$90-120$ & 49 & 26 & 110000 & 4959.38 & 15863.95 \\
$120-150$ & 50 & 39 & 110000 & 16362.10 \\
\hline
\end{tabular}

TABle 2: Arsenic sediment sampling location statistics for the Buffalo River ( $\mu \mathrm{g} / \mathrm{g})$.

\begin{tabular}{lccccc}
\hline Depth $(\mathrm{cm})$ & No. of sites & Min* & Max & Average & SD \\
\hline $0-30$ & 111 & 2.6 & 417.0 & 39.21 \\
$30-60$ & 34 & 3.2 & 357.0 & 26.78 & 16.35 \\
$60-90$ & 33 & 6.3 & 66.7 & 20.12 & 13.16 \\
$90-120$ & 49 & 4.4 & 164.0 & 31.58 \\
$120-150$ & 50 & 6.8 & 164.0 & 23.23 \\
\hline
\end{tabular}

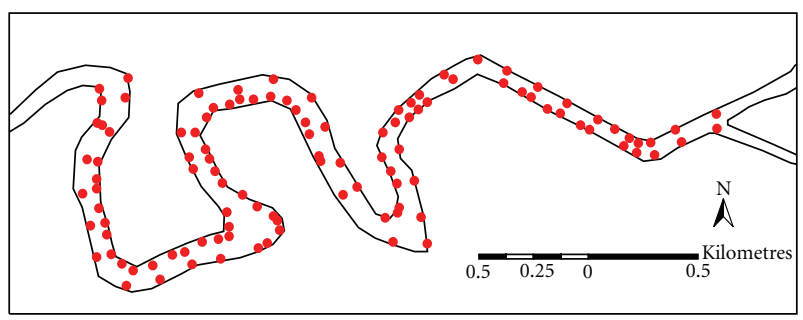

- 111 sample points

FIGURe 2: Distribution of sample points within the study area for surface sediments. Data source: NYSDEC (2008).

from the Buffalo River. This study used 111 surface samples seen in Figure 2 and 166 subsurface samples seen in Figure 3. Each sample point could have more than one data value associated with it due to a variation of contamination at different depths.

The data characteristics for anthracene and arsenic can be seen in Tables 1 and 2, respectively. One important note is that there is a large difference between the number of samples taken at the surface level and the number of samples taken at various subsurface depths. Although 166 subsurface samples were obtained (more than the surface samples), these were divided among four subsurface groups, each of which was independently analyzed. The original dataset that was provided did not contain sediment samples at every depth for each core. Additionally, it is interesting to see that for both anthracene and arsenic, the average contamination of each is slightly lower at the surface level when compared to the subsurface depths. Thus, it is more effective to analyze the sediment contamination of the Buffalo River at surface and subsurface levels to get the best representation of its true contamination.

\section{Methodology}

An ordinary kriging spatial interpolation technique was used to assess the surface and subsurface sediment contamination

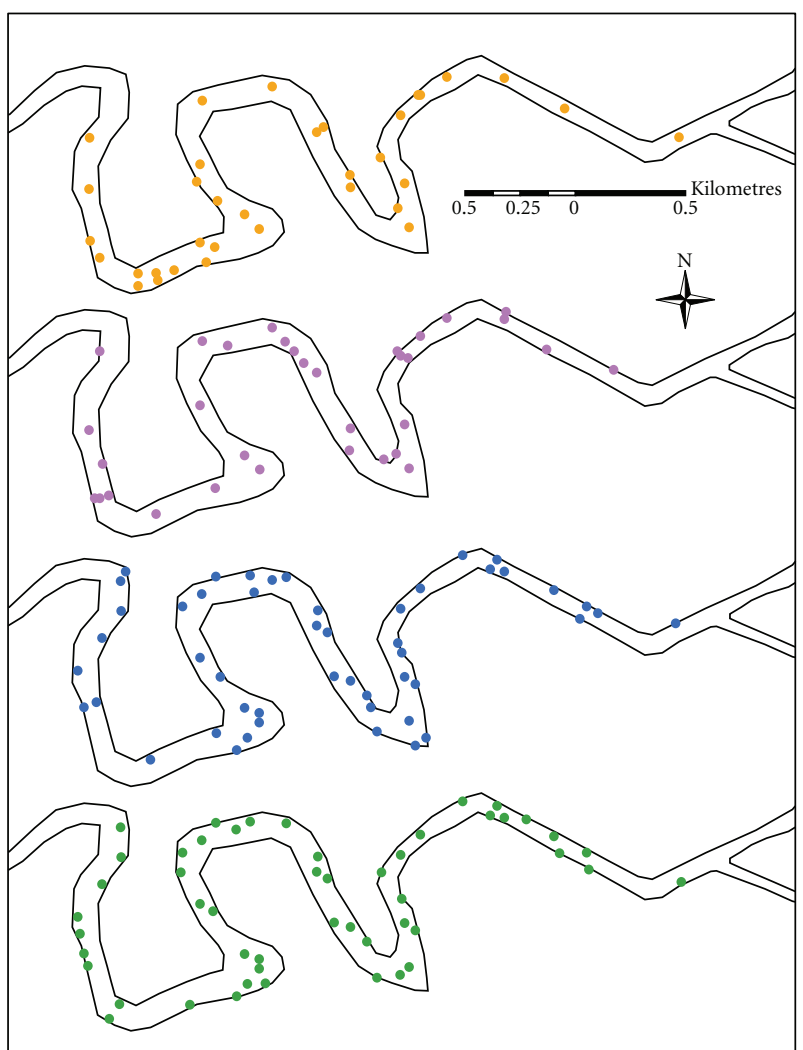

- Depth 30-60 cm (34 sample locations)

- Depth 60-90 cm (33 sample locations)

- Depth 90-120 cm (49 sample locations)

- Depth 120-150 cm (50 sample locations)

FIGURE 3: Distribution of sample points within the study area for subsurface sediments. Data source: NYSDEC (2008).

of the Buffalo River as it pertains to anthracene and arsenic. The analysis was run independently on each of the two contaminants and their associated subsurface depths. The kriging geospatial technique was originally developed for 
TABLE 3: Kriging log-normalized data cross-validation statistics for anthracene.

\begin{tabular}{lcccc}
\hline Depth $(\mathrm{cm})$ & Model & MPE & ASE & SRMSPE \\
\hline $0-30$ & Exponential & 0.0046 & 0.5150 & 0.9837 \\
$30-60$ & Gaussian & 0.0398 & 0.8171 & 0.9847 \\
$60-90$ & Spherical & 0.0038 & 0.7406 & 1.0270 \\
$90-120$ & Exponential & 0.0135 & 0.3492 & 1.0240 \\
$120-150$ & Gaussian & 0.0094 & 0.8895 & 0.9954 \\
\hline
\end{tabular}

TABLE 4: Kriging log-normalized data cross validation statistics for arsenic.

\begin{tabular}{lcccc}
\hline Depth $(\mathrm{cm})$ & Model & MPE & ASE & SRMSPE \\
\hline $0-30$ & Gaussian & 0.0002 & 0.2364 & 1.0280 \\
$30-60$ & Spherical & 0.0233 & 0.3507 & 1.0300 \\
$60-90$ & Spherical & 0.0014 & 0.2854 & 0.9491 \\
$90-120$ & Exponential & 0.0018 & 0.3492 & 1.0240 \\
$120-150$ & Exponential & 0.0017 & 0.3566 & 1.0180 \\
\hline
\end{tabular}

the mining industry to estimate ore reserves, but has been effectively been used to estimate sediment contamination [1618].

Since the Buffalo River meanders, the kriged prediction error maps for the entire study area may not be a true representation of the contamination within the Buffalo River. The technique "uses statistical models that are based on the assumption that spatial autocorrelation exists within a collection of sampled points" $[16,19]$. Rodriguez $[11]$ in his research found that the prediction error maps for mercury and lead contamination in the entire Buffalo River study area did not differ much from the results of the prediction error maps for three separate sections of the river.

The major advantage that the ordinary kriging technique has over other interpolation methods is that it can be statistically validated as it generates standard error surfaces $[16,18$, 20]. The most suitable parameters to use when performing a kriging interpolation for the Buffalo River study area through the geostatistical wizard in ESRI's ArcMap are as follows: maximum range: 900, minimum range: 300, direction: 90, neighbours to include: 5 , include at least: 1 [7]. These criteria were chosen after experimentation as they produced the most accurate results, when compared to other options. To achieve the most ideal kriging results, the most appropriate kriging method (Spherical, Exponential, or Gaussian) should be evaluated. To determine the best model, the ideal criteria are as follows: the mean prediction error (MPE) should be as close to 0 as possible, the root-mean square prediction error (RMSPE) and average standard error (ASE) should be similar and both should not be more than 20 (with smaller values being more ideal), and the standardized root-mean squared prediction error (SRMSPE) should be as close to 1 as possible $[10,16,20]$. If the RMS and ASE are greater than 20, then the actual values at each of the sampled locations are not close to the predicted values at those locations $[10,16,20]$. When the SRMSPE is greater than 1 , then the variability of predictions is underestimated, and when the SRMSPE is less than 1, then the variability of predictions is overestimated [18, 21].

A log transformation may need to be conducted if the kriging error results are not statistically valid. Although it is not necessary to log-transform data used by the kriging interpolator, data that are normally distributed are better suited for kriging analysis [16]. Ouyang et al. [22] recommend log transformations for non-normally distributed datasets because the skewness warrants some type of standardization. Missing values within the dataset need to be assigned a generic value, not zero, to ensure that they are omitted from the transformations and results. A base ten log function "LG10()" in SPSS was used to standardize the data.

4.1. Log Transformations. After running the ordinary kriging spatial interpolator on the anthracene data, the best suited models were not statistically valid at the surface or subsurface levels so they were log-transformed. Table 3 shows the logtransformed cross validation statistics for anthracene at all depths, which are all considered to achieve the most suitable kriging statistics $[16,18,20]$. The best suited model chosen at various depths included all three models considered: Spherical, Exponential, and Gaussian. The variability of predictions is slightly underestimated at subsurface depths of $60-90 \mathrm{~cm}$ and $90-120 \mathrm{~cm}$, while the variability of predictions is slightly overestimated at surface level and subsurface depths at 30$60 \mathrm{~cm}$ and $120-150 \mathrm{~cm}$.

After running the ordinary kriging spatial interpolator on the arsenic data, the best suited models were not statistically valid at the surface or subsurface levels, except at a subsurface depth of $60-90 \mathrm{~cm}$. It was decided to log-transform all the depths to maintain consistency when comparing the results between the depths. The cross-validation results can be seen in Table 4. Again these results are considered to achieve the most suitable kriging statistics. Similar to the case for anthracene, the best models varied for the different depths and included Spherical, Exponential, and Gaussian. Further, the models slightly underestimated the variability of prediction at all depths except for the 60-90 cm subsurface depth.

\section{Results}

5.1. Anthracene. The surface sediment contamination of anthracene is depicted in Figure 4. The surface contamination 


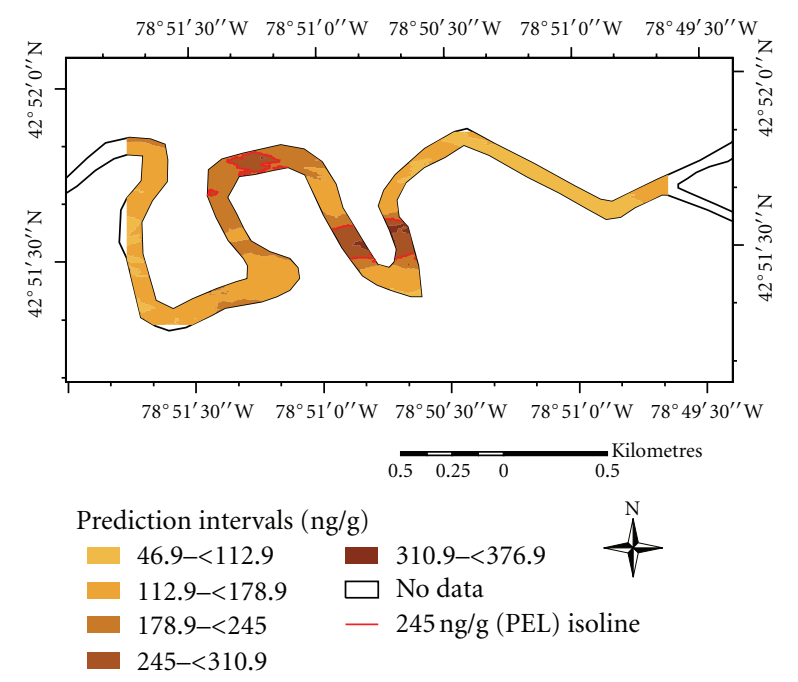

FIgURE 4: 2005 kriged anthracene log-normal concentrations at surface level.

is least contaminated when compared to the subsurface levels. The majority of the river appears to be contaminated between the TEL and PEL levels. Although the portions of the river that fall between these TEL and PEL levels are of interest, the areas where contamination is above the PEL level are most concerning. There is a small cluster of heavy contamination in the central portion of the river. High levels of anthracene contamination here are located on both sides of the meander. Also, a smaller section in the northern portion of the study area is contaminated above the PEL level. The immediate areas surrounding these sections of the river that are above the PEL are still heavily contaminated and are near the probable effect levels. There are no TEL isolines in Figure 4 because concentration levels for anthracene are all above this level. Figure 5 shows the sample locations and contamination levels for anthracene at the surface level. Since there are 111 sample locations in the study area, the proportional circle map appears slightly cluttered. Likewise, the majority of the sample points have anthracene concentrations between the TEL and PEL (46.9 ng/g and $245 \mathrm{ng} / \mathrm{g}$ ) making the map appear somewhat uniform. Variation in contamination concentrations between sample points in this class is difficult to identify. Further, there are samples taken that have anthracene concentrations below the TEL; however, these are few in number and are scattered throughout the study area.

The subsurface sediment contamination of anthracene at various subsurface depths ranging from 30 to $150 \mathrm{~cm}$ can be seen in Figure 6. Sediment at a depth of 30-60 cm is located directly under the surface sediment. The contamination at this depth is more severe than that of the surface level. There is only a small PEL isoline located in the western section of the study area that separates a small northern portion that is contaminated between the TEL and PEL and the rest of the river that is contaminated above the PEL. Further, there is a very small portion of the river in the north-central section that is below the PEL and classified between $112.9 \mathrm{ng} / \mathrm{g}$ and $178.9 \mathrm{ng} / \mathrm{g}$, but it surrounded by heavier contamination. What is most concerning is that not only is the majority of

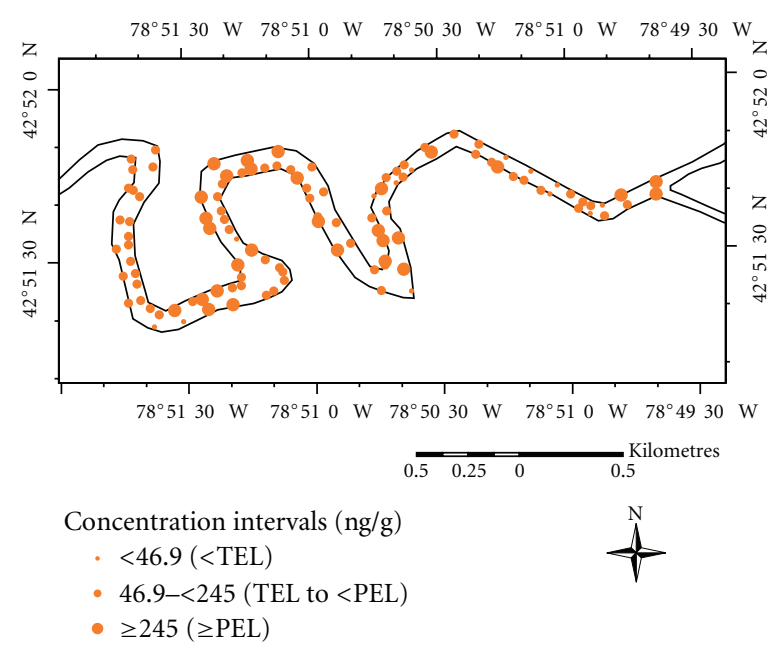

FIGURE 5: 2005 anthracene log-normal concentrations at surface level.
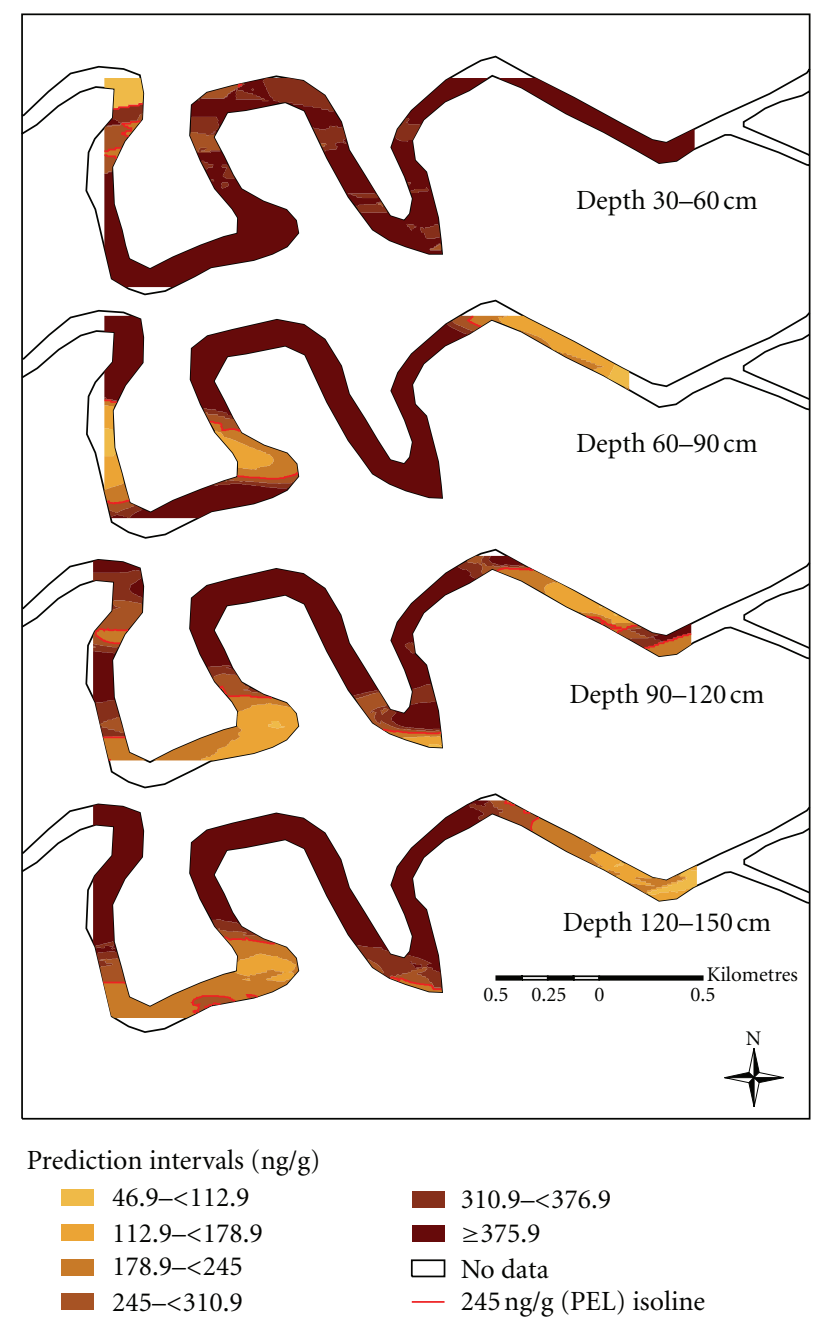

FIGURE 6: 2005 kriged anthracene log-normal concentrations at surface level. 
contamination above the PEL at this depth, but most of the river falls in the final kriged class, which has contamination greater than or equal to $376.9 \mathrm{ng} / \mathrm{g}$. Since the pollution is so heavy here, there is no surprise that there are no TEL isolines and no segment of the river is below that TEL.

The distribution of anthracene contamination at a subsurface depth of $60-90 \mathrm{~cm}$ appears to be less contaminated when compared to the depth above. The central segment of the river is heavily contaminated above the PEL at the highest class, greater than or equal to $376.9 \mathrm{ng} / \mathrm{g}$. The eastern portion and part of the western portion of the river are less contaminated as contamination falls between the TEL and PEL, but then increase in contamination concentrations. The increase to heavy contamination is fairly sudden as the sections classified between $245 \mathrm{ng} / \mathrm{g}$ and $376.9 \mathrm{ng} / \mathrm{g}$ is very small. Further the least contaminated areas, between $46.9 \mathrm{ng} / \mathrm{g}$ and $112.9 \mathrm{ng} / \mathrm{g}$, are located in the western and eastern sections of the river and are small. The contamination in these areas is still above the TEL, thus, no sections of the river at this subsurface depth are classified below the TEL and considered to have minimal contamination.

The subsurface sediment contamination of anthracene at the next subsurface depth of $90-120 \mathrm{~cm}$ follows a similar pattern to that of the above depth at $60-90 \mathrm{~cm}$. The central portion of the river is heavily contaminated with anthracene as it is greater than or equal to $376.9 \mathrm{ng} / \mathrm{g}$. The south central section of the river has a small area that is classified between the TEL and PEL, as this section is less contaminated than the depth above. Although the area directly above is still contaminated above the PEL, it is not as contaminated as the above depth since a small section here is between the $245 \mathrm{ng} / \mathrm{g}$ and $376.9 \mathrm{ng} / \mathrm{g}$ range. Also, the eastern portion of the river is mostly between the TEL and PEL, but does contain a small portion above the TEL. Moreover, the western segment of the river is more contaminated than the above depth with a much smaller pocket between the TEL and PEL, but decreases in the south-western area. Again, no portion of the river at this depth is contaminated below the TEL, thus still remaining a concern.

The pattern of anthracene distribution at the deepest subsurface depth of $120-150 \mathrm{~cm}$ is similar to the two depths above. The central section of the river is heavily contaminated above the PEL. Most of this portion is contaminated at a concentration greater than or equal to $376.9 \mathrm{ng} / \mathrm{g}$. Similar to the above depth, which is slightly different than at the 60$90 \mathrm{~cm}$ depth, there is a small section in the south-central area that is a little less contaminated and just below the PEL. Further, the eastern section of the river is less contaminated than the central section as the concentrations are between the TEL and PEL, but the contamination level here is still concerning. Also, the south-west section of the river is mostly contaminated between the TEL and PEL, with only a small area of anthracene concentrations above the PEL. The northwest section of the river is heavily contaminated with contamination levels similar to those of the central portion of the river.

5.2. Arsenic. The surface sediment contamination of arsenic is depicted in Figure 7. Similarly to the case with anthracene,

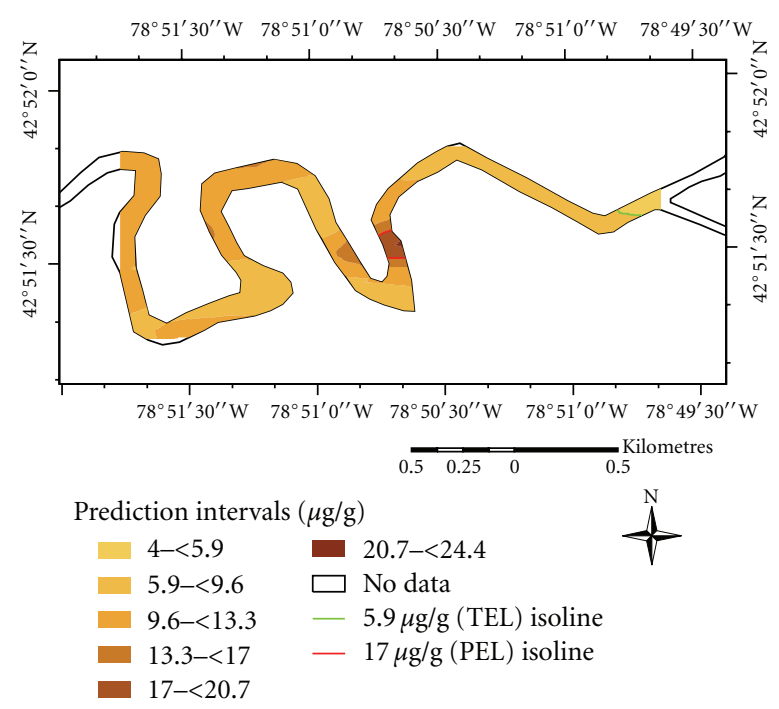

FIGURE 7: 2005 kriged arsenic log-normal concentrations at surface level.

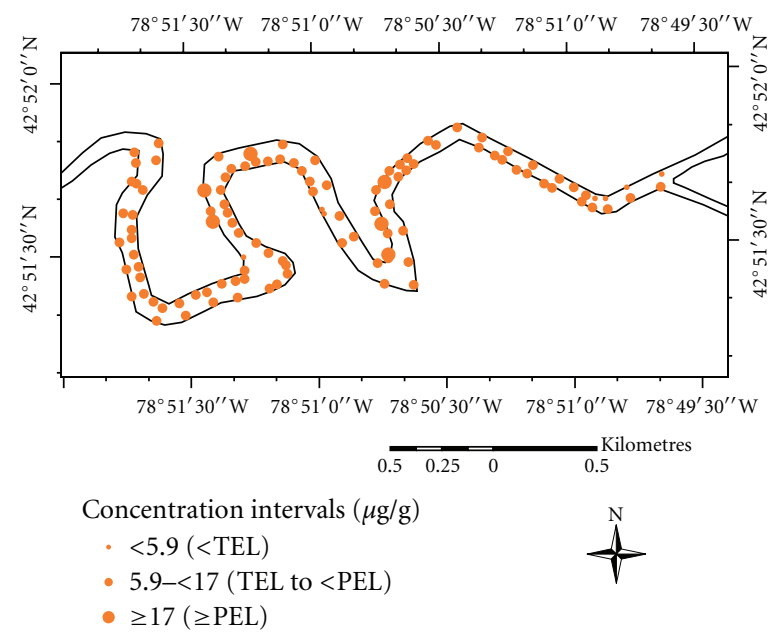

FIGURE 8: 2005 arsenic log-normal sample concentrations at surface level.

the surface contamination is least contaminated when compared to the subsurface levels. The Buffalo River is less contaminated with arsenic when compared to anthracene. The eastern section of the river has a TEL isoline, which was not present for anthracene contamination concentrations at the surface or any subsurface levels. This small area has arsenic concentrations just below the TEL. Further, the arsenic concentrations at the surface level appear to be fairly uniform throughout the river. Although the river appears less contaminated with arsenic when compared to anthracene, concentrations here are mostly categorized between the TEL and PEL and still concerning as adverse biological effects are likely to occur. Furthermore, the central section of the river has a small area that is above the PEL and is most alarming; however, the concentrations of arsenic here are just above the PEL and not too heavily contaminated. Figure 8 shows the distribution of arsenic concentrations by sample locations. There 
is a small cluster of sample locations in the east that have concentrations below the TEL. These points contribute to the creation of a TEL isoline in the kriged map. There are other sample locations in the central section of the river that have arsenic concentrations below the TEL; however, they are surrounded by more heavily contaminated sample locations, which prevent the creation of a TEL isoline.

Figure 9 shows the arsenic concentrations at various subsurface depths between 30 and $150 \mathrm{~cm}$. Arsenic contamination at a depth of $30-60 \mathrm{~cm}$ is more severe when compared to the surface level above. There are clusters of heavy contamination scattered throughout the river. Similar to the above depth, the central section of the river is mostly contaminated between the TEL and PEL with a larger cluster of arsenic contamination above the PEL. This level of contamination is located on both the downstream and upstream sections. Also, there is a large area in the eastern portion of the river that is heavily contaminated above the PEL at concentrations greater than or equal to $24.4 \mu \mathrm{g} / \mathrm{g}$. Moreover, the western portion of the river has a sudden change in contamination as the southern section is contaminated above the PEL, while the northern section has a small area contaminated below the TEL.

The distribution of arsenic at a subsurface depth of 60 $90 \mathrm{~cm}$ does not contain any TEL isolines. The concentrations of arsenic within the rivers' sediment follow a uniform pattern throughout. The majority of the river at this depth has arsenic concentrations between $9.6 \mu \mathrm{g} / \mathrm{g}$ and $17 \mu \mathrm{g} / \mathrm{g}$. The heaviest contamination and largest classification grouping is concentrated in the central section of the river. The southwestern and eastern portions of the river are slightly less contaminated, but contamination levels are still between the TEL and PEL. There are also some small clustered areas where arsenic contamination is above the PEL and most concerning. These are mostly located in the central section of the river, where contamination is heaviest, but are also present in the north-western section of the river.

The sediment contamination at the next subsurface depth of $90-120 \mathrm{~cm}$ has contamination levels above the TEL in all areas. The heaviest arsenic contamination at this depth is located in the central section of the river. The upstream portion here is more contaminated with a large area above the PEL when compared to the downstream portion, which has smaller clusters of heavy contamination above the PEL. Also, there are PEL isolines located in the western section of the river, where there is a small pocket of heavy contamination. Further, the eastern section of the river is less polluted with arsenic as concentrations are between $9.6 \mu \mathrm{g} / \mathrm{g}$ and $17 \mu \mathrm{g} / \mathrm{g}$.

Similar to the depth above, the central section of the river at a depth of $120-150 \mathrm{~cm}$ is polluted the most with arsenic. The contamination is heavier here as the PEL isolines encompass larger areas both on the downstream and upstream sections of the central part of the river. Further, the western section of the river has heavy arsenic contamination at this depth that is similar to that of the above depth. The area here that has arsenic concentrations greater than or equal to $17 \mu \mathrm{g} / \mathrm{g}$ is larger than the above depth and decreases more gradually. Also, the eastern portion of the river is similarly

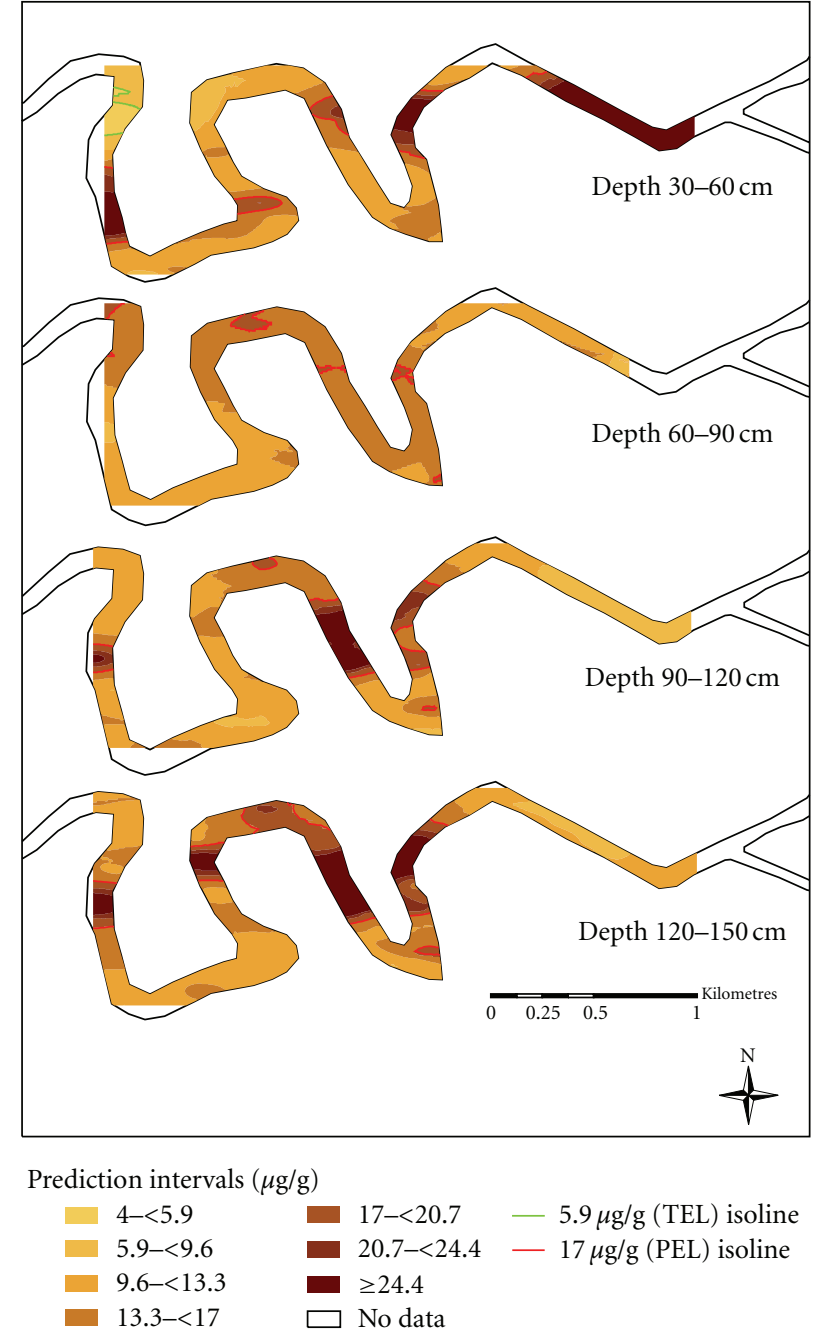

FIGURE 9: 2005 kriged arsenic log-normal concentrations at surface level.

contaminated to the depth above with arsenic concentrations ranging between the TEL and PEL.

\section{Discussion}

The Buffalo River is heavily contaminated with anthracene and arsenic. Areas with contamination concentrations that are above the PEL are most concerning, while areas that have contamination concentrations between the TEL and PEL are less concerning, but still important. Areas below the TEL, which are few in this study, do not pose a great threat to the aquatic ecosystem. The distribution of sample locations between the three chosen class divisions can be seen in Table 5 for anthracene and in Table 6 for arsenic. Generally, the river is more heavily contaminated with anthracene as compared to arsenic. Anthracene concentrations above the PEL are a lot larger in proportion to concentrations between the TEL and PEL as compared to arsenic.

Both anthracene and arsenic concentrations at the surface level are lower when compared to the various subsurface 
TABLE 5: Number of anthracene sediment sampling locations in relation to TEL and PEL categories.

\begin{tabular}{lcccc}
\hline Depth $(\mathrm{cm})$ & No. of sites & $<$ TEL & TEL and $<$ PEL & 29 \\
\hline $0-30$ & 111 & 13 & 16 & 29 \\
$30-60$ & 34 & 0 & 15 & 18 \\
$60-90$ & 33 & 0 & 22 & 26 \\
$90-120$ & 49 & 1 & 24 & 25 \\
$120-150$ & 50 & 1 & & 24 \\
\hline
\end{tabular}

TABLE 6: Number of arsenic sediment sampling locations in relation to TEL and PEL categories.

\begin{tabular}{lcccc}
\hline Depth $(\mathrm{cm})$ & No. of sites & $<$ TEL & T TEL and $<$ PEL & (PEL \\
\hline $0-30$ & 111 & 7 & 22 & 68 \\
$30-60$ & 34 & 2 & 23 & 10 \\
$60-90$ & 33 & 2 & 37 & 10 \\
$90-120$ & 49 & 0 & 36 & 10 \\
$120-150$ & 50 & & 14 \\
\hline
\end{tabular}

depths. As seen in Tables 5 and 6 , there are proportionately more sample points within the $\geq$ TEL and $<$ PEL class than the $\geq$ PEL class at the surface level when compared to the subsurface depths. Current conditions, being 2005, of biological active strata are identified by surface sediments, while subsurface sediments represent the history of contaminant depositional patterns [15]. Further, the subsurface distribution of anthracene appears to be fairly uniform throughout all depths. One underlying pattern that appears to exist is that anthracene contamination within Buffalo River sediments is greatest at a subsurface depth of $30-60 \mathrm{~cm}$ and then tends to gradually decrease within deeper sediment. This can be seen by comparing Figures 4 to 6 . No obvious pattern of arsenic contamination can be seen when comparing the subsurface depths in Figure 8, except that key areas of concern can be identified.

Key areas of concern have been identified in both the anthracene and arsenic contamination maps. Figures 4, 6, 7, and 9 identify the central section of the Buffalo River study area as the most concerning, with contamination levels above the PEL on both the downstream and upstream sections of the river. The reason why these areas are important is because they represent the highest contamination concentrations, which are above the PEL, making adverse biological effects likely to occur. Since dredging is occurring to restore the rivers' health, these heavily contaminated areas need to be identified and suggested as sites to be dredged to reduce remediation costs.

One important note is that Tables 5 and 6 and Figures 5 and 8 group data into fewer classes and do not display a detailed level of contamination concentrations in the Buffalo River. The kriging spatial interpolation technique eliminates this issue, making kriging more effective than viewing traditional proportional circle maps. When comparing the kriged maps in Figures 4 and 7 to the proportional circle maps in Figures 5 and 8, the kriged maps show more information. With proportional circle maps, the viewer needs to guess or estimate how contamination levels vary between sample locations, which are what the kriged maps display.

\section{Conclusion}

This research was completed to determine the extent of contamination within the Buffalo River. The New York State Department of Environmental Conservation collected the data used in this research. Both anthracene and arsenic concentrations were mapped using the kriging spatial interpolation technique to identify areas where sediment contamination was most concerning. Analysing a PAH and metalloid presented a good measure of the real contamination within Buffalo River sediments.

The Buffalo River was more contaminated with anthracene as compared to arsenic. The surface layer is a lot less contaminated than the subsurface layers in both cases, which can be linked to the labelling of the Buffalo River as an area of concern by the Great Lakes Water Quality Agreement between Canada and the United States. Since then more quality control measures have been implemented by the government, including holding major corporations accountable for the environmental damage. Current discharges and other sources of contamination have decreased which can be attributed to less contamination of the surface layer; however, historic contamination still plays a factor as deeper sediments are heavily contaminated. Based on the results of the study, it can be concluded that the Buffalo River should still be an Area of Concern as historical contamination is still present within the river sediment and appropriate actions should be taken to restore its health. Dredging may be a good option in restoring the natural habitat of the river, and key areas outlined in this research should be considered as suitable sites.

\section{References}

[1] J. Tokasz, "Group intent on Buffalo River cleanup; \$39 million plan targets removal of contaminants," Buffalo News, p. B5, 2010.

[2] S. Inamdar, Sediment Modeling for the Buffalo River Watershed, Great Lakes Center, Buffalo, NY, USA, 2004. 
[3] US EPA, Anthracene Fact Sheet, http://www.epa.gov/wastes/ hazard/wastemin/minimize/factshts/anthrace.pdf.

[4] J. E. Djomo, P. Garrigues, and J. F. Narbonne, "Uptake and depuration of polycyclic aromatic hydrocarbons from sediment by the zebrafish (Brachydanio rerio)," Environmental Toxicology and Chemistry, vol. 15, no. 7, pp. 1177-1181, 1996.

[5] P. Baumard, H. Budzinski, and P. Garrigues, "Polycyclic aromatic hydrocarbons in sediments and mussels of the Western Mediterranean Sea," Environmental Toxicology and Chemistry, vol. 17, no. 5, pp. 765-776, 1998.

[6] Health Canada, Arsenic in Drinking Water, http://www.hc-sc. gc.ca/hl-vs/iyh-vsv/environ/arsenic-eng.php.

[7] K. W. Forsythe, A. Gawedzki, and P. S. Rodriguez, "Assessing sediment contamination in the Buffalo river," in Proceedings of the 22nd Symposium for Applied Geographic Information Processing (Angewandte Geographische Informationsverarbeitung XXII), (AGIT '10), J. Strobl, T. Blaschke, and G. Griesebner, Eds., pp. 606-615, Herbert Wichmann Verlag, Salzburg, Austria, July 2010.

[8] M. Berg, H. C. Tran, T. C. Nguyen, H. V. Pham, R. Schertenleib, and W. Giger, "Arsenic contamination of groundwater and drinking water in Vietnam: a human health threat," Environmental Science and Technology, vol. 35, no. 13, pp. 26212626, 2001.

[9] D. N. G. Mazumder, R. Haque, N. Ghosh et al., "Arsenic in drinking water and the prevalence of respiratory effects in West Bengal, India," International Journal of Epidemiology, vol. 29, no. 6, pp. 1047-1052, 2000.

[10] K. W. Forsythe and C. H. Marvin, "Assessing historical versus contemporary mercury and lead contamination in Lake Huron sediments," Aquatic Ecosystem Health and Management, vol. 12, no. 1, pp. 101-109, 2009.

[11] P. Rodriguez, Assessing the geographic distribution of mercury and lead in Buffalo river sediments, Unpublished Master of Spatial Analysis Major Research Paper, Department of Geography, Ryerson University, 2009.

[12] Great Lakes Information Network (GLIN), Great Lakes Facts and Figures, 2004, http://www.great-lakes.net/lakes/ref/lakefact.html.

[13] K. N. Irvine and G. W. Pettibone, "Dynamics of indicator bacteria populations in sediment and river water near a combined sewer outfall," Environmental Technology, vol. 14, no. 6, pp. 531-542, 1993.

[14] T. J. Canfield, F. J. Dwyer, J. F. Fairchild et al., "Assessing contamination in Great Lakes sediments using benthic invertebrate communities and the sediment quality triad approach," Journal of Great Lakes Research, vol. 22, no. 3, pp. 565-583, 1996.

[15] G. P. Sutton, Buffalo Sediment Study, New York State Department of Environmental Conservation, Buffalo, NY, USA, 2006.

[16] K. W. Forsythe, K. Paudel, and C. H. Marvin, "Geospatial analysis of zinc contamination in Lake Ontario sediments," Journal of Environmental Informatics, vol. 16, no. 1, pp. 1-10, 2010.

[17] T. C. Bailey and A. C. Gatrell, Interactive Spatial Data Analysis, Longman Group Limited, 1995.

[18] K. Johnston, J. M. VerHoef, K. Krivoruchko, and N. Lucas, Using ArcGIS Geostatistical Analyst, Environmental Systems Research Institute, Redlands, Calif, USA, 2001.

[19] Y. Ouyang, J. Higman, D. Campbell, and J. Davis, "Threedimensional kriging analysis of sediment mercury distribution: a case study," Journal of the American Water Resources Association, vol. 39, no. 3, pp. 689-702, 2003.
[20] D. J. Jakubek and K. W. Forsythe, "A GIS-based kriging approach for assessing Lake Ontario sediment contamination," Great Lakes Geographer, vol. 11, no. 1, pp. 1-14, 2004.

[21] K. W. Forsythe and C. H. Marvin, "Analyzing the spatial distribution of sediment contamination in the lower Great Lakes," Water Quality Research Journal of Canada, vol. 40, no. 4, pp. 389-401, 2005.

[22] Y. Ouyang, P. Nkedi-Kizza, R. S. Mansell, and J. Y. Ren, "Spatial distribution of DDT in sediments from estuarine rivers of central Florida," Journal of Environmental Quality, vol. 32, no. 5, pp. 1710-1716, 2003. 

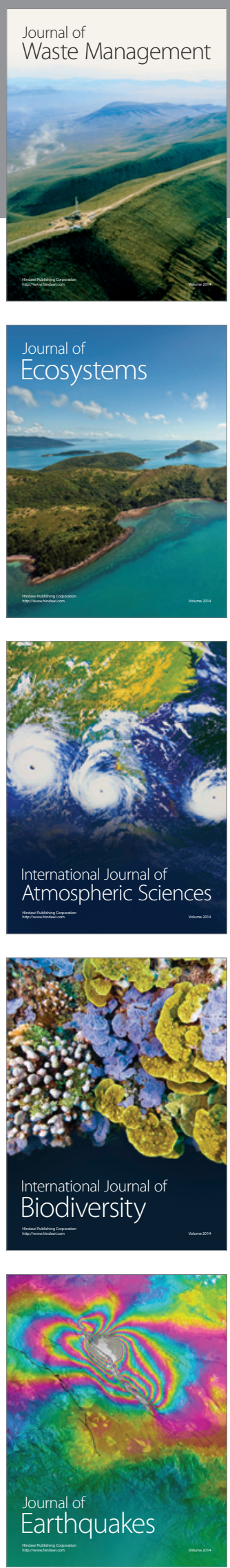
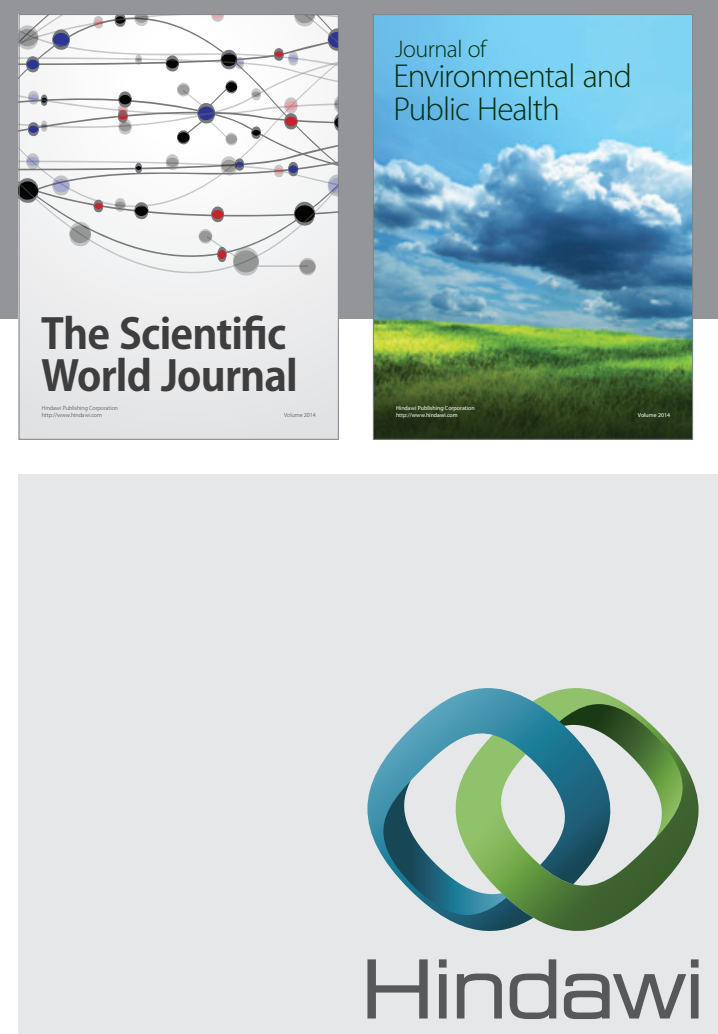

Submit your manuscripts at

http://www.hindawi.com
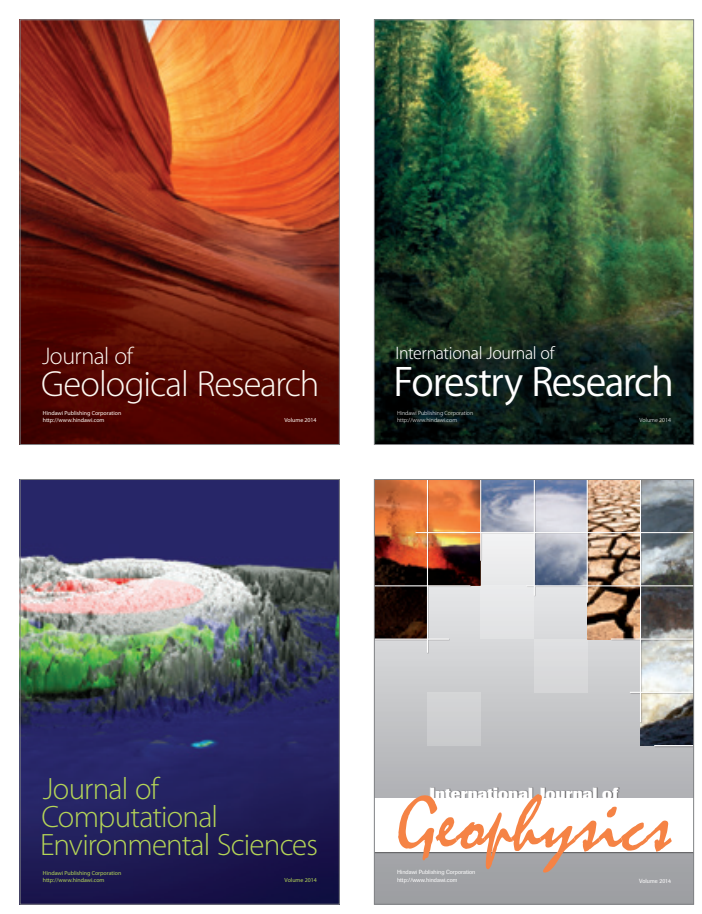
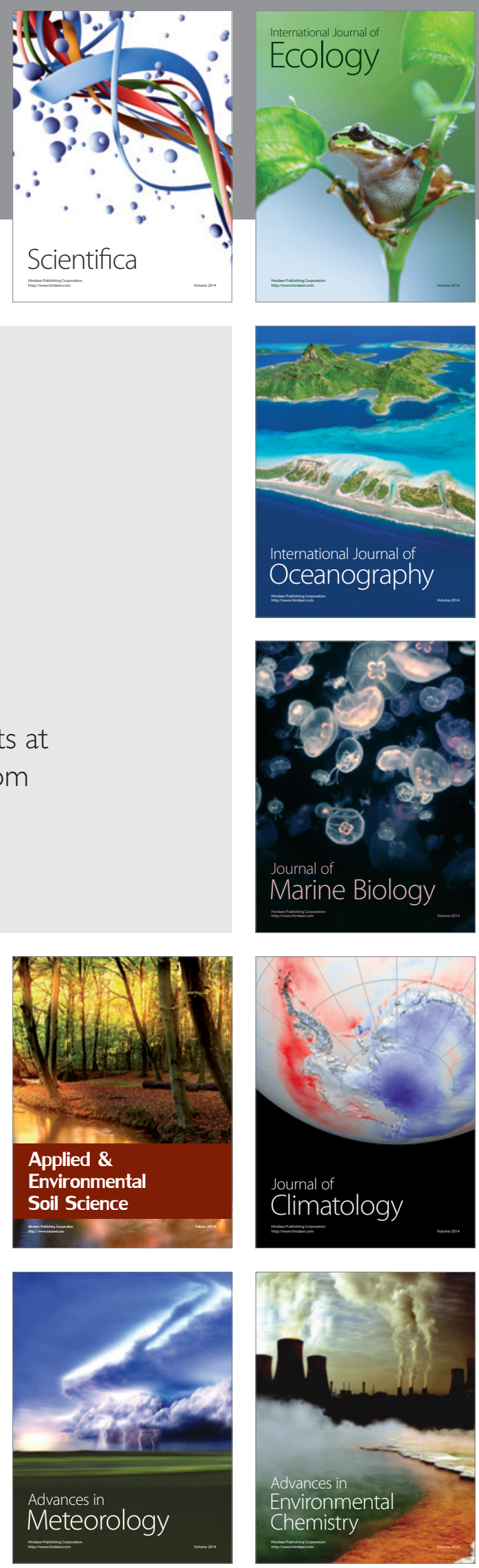